\title{
Staphylococcus aureus Binding Proteins for Prevention of Orthopaedic Implant-Related Infections
}

\section{Elizabeth Ratcliffe*}

Healthcare Engineering Research Group, Centre for Biological Engineering, Wolfson School of Mechanical and Manufacturing Engineering, Loughborough University, Loughborough, Leicestershire, UK

\begin{abstract}
Orthopaedic implant infections are an increasing problem and management commonly involves implant removal with serious consequences. Biofilm-forming staphylococci are the most common causative organisms, with Staphylococcus aureus being the most virulent and MRSA increasingly involved. Initial bacterial adhesion is a crucial event in biofilm formation and infection establishment. Directing host antibody against bacterial factors involved in adhesion and biofilm formation may significantly inhibit infection establishment on biomaterials. Two recombinant $S$. aureus-derived binding proteins (FnBP, IsdA) were investigated as potential vaccine antigens and resultant antibody was assessed to determine whether immune inhibition of bacteria-ligand binding can significantly impact on attachment to plasma-conditioned biomaterial surfaces, in the presence of other bacterial ligands.

Adhesion of homologous and heterologous (clinical MRSA) S. aureus to plasma-conditioned steel was significantly reduced $(\sim 50 \%$ average reduction, $p<0.0001)$ when pre-exposed to anti-rFnBP-A antiserum that was 50 -fold more dilute than the actual titre from immunisation. Inhibition was related to ligand presence and not staphylococcal Protein A. Reduced adhesion was not observed with an FnBP-mutant strain, indicating specific inhibitory antibody involvement, and demonstrating the potential of rFnBP-A for prevention of $S$. aureus implantrelated infection. Adhesion-inhibitory activity was also observed with a purified IgG-fraction of rlsdA antiserum but this activity appeared to be masked by non-IsdA-related interactions when non-IgG-purified antiserum was assessed.
\end{abstract}

Keywords: Staphylococcus aureus; Orthopaedic; Implant; Infection; Vaccine; Binding proteins; Nosocomial

\section{Introduction}

Infections associated with implanted medical devices such as joint arthroplasty prostheses are an increasing problem due to mounting antibiotic resistance/insusceptibility of common causative organisms, and increased requirement by a more numerous ageing population. Antibiotics are crucial for prevention of infection during joint replacement implantation procedures [1]. Antibiotics are also the mainstay infection treatment option, in addition to debridement and removal of infected tissue and implanted biomaterials [1-3]. Prosthesis and tissue removal is the most common and typically only option for curing an infection, resulting in serious health, social and economic consequences (increased morbidity, mortality, prolonged hospital stay). The major source of intra-operative bacterial contamination in joint replacement surgery and other orthopaedic implant surgery is patient skin-derived bacteria $[1,4]$. Biofilm-forming staphylococci are the most common causative organisms, with Staphylococcus aureus being most virulent and responsible for approximately half the infections [4]. Staphylococcal resistance to antibiotics is mounting and increasingly Meticillin-Resistant S. aureus (MRSA) is involved in implant infections. The outcome of infection is significantly poorer if the causative organism is resistant to antibiotics [5-11] and MRSA more than doubles the infection mortality rate [5].

Bacterial biofilm formation during infection establishment also leads to reduced susceptibility of quiescent cells embedded within the biofilm and antibiotic treatment failure $[12,13]$. Insusceptibility to combined antibiotics [14], bacterial persistence in the face of an immune response [15], and enhanced transfer of resistance elements [16] are also key problems associated with biofilm infection. Initial bacterial adhesion to the host plasma-conditioned prosthesis and surrounding tissue mediated by bacterial-binding proteins is a primary event in biofilm formation [17-19], followed by intercellular adhesion and formation of multi-cellular layers (biofilm) [15]. Although bacteria can establish infection at the implant surface and in the peri-implant tissue, there is evidence to suggest that bacteria at the implant surface may be more important for infection persistence and worse outcome for the patient [20]. Binding of S. aureus to plasma glycoproteins (Fgfibrinogen, Fn-fibronectin) that coat implanted biomaterial (and aid binding to tissues) is important in initiation of biomaterial-related infection [17-19], and the two most potent $S$. aureus binding proteins that have been shown to be important for this interaction are the fibronectin-binding protein (FnBP) and fibrinogen-binding ironsurface determinant (IsdA).

Binding to fibronectin appears to be an extremely important mechanism during $S$. aureus infection, evidenced by the duplicity of binding protein expression (FnBP-A, FnBP-B), the multiplicity of Fnbinding domains and functions of each protein [21-26]. Almost all clinical isolates express the FnBP's singly or in combination $[27,28]$, FnBP-A is expressed by all of the most prevalent epidemic MRSA (EMRSA) clones in the UK [29-31] and prevalence of the fnb genes is extremely high among orthopaedic isolates (99\% of 191 isolates) [28]. Fusion proteins comprising the $\beta$-galactosidase gene from $E$.

*Corresponding authors: Dr. Elizabeth Ratcliffe, Postdoctoral Research Associate, Healthcare Engineering Research Group, Centre for Biological Engineering, Wolfson School of Mechanical and Manufacturing Engineering, Loughborough University, Loughborough, Leicestershire, LE11 3TU, UK, Tel: +44(0)1509 564 889; E-mail: E.Ratcliffe@|boro.ac.uk

Received June 17, 2014; Accepted July 05, 2014; Published July 11, 2014

Citation: Ratcliffe E (2014) Staphylococcus aureus Binding Proteins for Prevention of Orthopaedic Implant-Related Infections. J Microb Biochem Technol 6: 303-313. doi:10.4172/1948-5948.1000160

Copyright: (c) 2014 Ratcliffe E. This is an open-access article distributed under the terms of the Creative Commons Attribution License, which permits unrestricted use, distribution, and reproduction in any medium, provided the original author and source are credited 
coli and full-length FnBP-A, truncated binding-domain sequences (D-domain), or complete recombinant FnBP-A have demonstrated partial protection as immunogens in animal models of endocarditis and mastitis infections [32,33]. Fibrinogen binding is also extremely important for infection establishment and of the fibrinogen-binding proteins expressed by S. aureus, Clumping factor A (ClfA) is considered of premier importance and best characterised. However, the hemescavenging broad spectrum adhesin termed the iron-regulated surface determinant protein A (IsdA) was previously shown to bind fibrinogen and fibronectin under iron-limited conditions in-vitro, with its affinity for fibrinogen being 20-fold higher than that determined for the ClfA binding domain [34]. Evidence suggests that IsdA has multiple functions and plays a role in iron-acquisition [35,36], it is also known to be expressed during growth in human serum [37] and screening of serum samples from patients convalescing from $S$. aureus infections demonstrated the expression of IsdA during infection [34]. IsdA has been investigated as a vaccine antigen to prevent haematogenous $S$. aureus infection and lethal challenge $[38,39]$ was also recently shown to be important for nasal carriage as vaccination with recombinant IsdA significantly reduced $S$. aureus nasal carriage in cotton rats [40].

Pre-operative vaccination in elective orthopaedic cases could be a viable alternative approach for prevention of infection to reduce both infection rate and severity. There are increasing requirements to develop complimentary preventive strategies without giving rise to antibiotic resistance or undesirable implant/fixative effects on integration. A vaccine against staphylococcal biomaterial-related infection will likely target multiple surface expressed virulence factors from $S$. aureus and S. epidermidis (significant causative organism) that are crucial to bacterial adherence and biofilm formation. This paper describes the in vitro investigations of two potential $S$. aureus vaccine candidates to determine whether antibody directed against staphylococcal binding protein is capable of inhibiting bacterial attachment to plasmaconditioned biomaterials.

\section{Methods}

\section{Bacterial strains, plasmids, sequences and culture conditions}

Table 1 lists the bacterial strains used in this study. Staphylococcal strains were routinely cultured aerobically at $37^{\circ} \mathrm{C}$ on Blood agar base No. 2 with sheep blood or Tryptic Soy Agar (TSA). Aerobic $37^{\circ} \mathrm{C}$ broth cultures used Tryptic Soy Broth (TSB) (Oxoid, Basingstoke, UK) or Chemically Defined Metal Limitation (CL) medium [41] with $200 \mathrm{rpm}$ aeration, and supplemented with $5 \mu \mathrm{g} \mathrm{ml}^{-1}$ erythromycin, tetracycline, or $1 \mu \mathrm{M} \mathrm{ml}^{-1}$ ferric chloride $\left(\mathrm{FeCl}_{3}\right)$ where appropriate (Sigma-Aldrich Ltd., Dorset, UK). Strains were characterized using standard techniques including antibiogram and API Staph, and expression/non-expression of target protein was confirmed by western immunoblotting analysis.

E. coli strains were routinely cultured aerobically on Luria-Bertani (LB) agar, or medium [42] with $250 \mathrm{rpm}$ aeration, and supplemented with $100 \mu \mathrm{g} \mathrm{ml}^{-1}$ ampicillin or $50 \mu \mathrm{g} \mathrm{ml}^{-1}$ kanamycin where appropriate (Sigma). Bacterial growth was monitored by absorbance at $600 \mathrm{~nm}$ for E. coli cultures and $490 \mathrm{~nm}$ for staphylococcal cultures using an Ultraspec 2000 spectrophotometer (Pharmacia Biotech, Cambridge, UK).

The amino acid sequence and organization of the FnBP-A protein from S. aureus 8325-4 is shown in Figure 1, where the purified domain is highlighted. Although our interest lies in the knowledge that IsdA is a potent fibrinogen binding protein, we were also interested in IsdA as a general adhesin capable of binding multiple ligands potentially in the establishment of orthopaedic implant infections. Therefore full length IsdA rather than the NEAT domain was used in this study (Figure 2).

\section{Bacterial cell clumping assay}

To confirm IsdA expression during culture of S. aureus SH1000 under conditions appropriate for the adhesion assays, the ability of cellsurface exposed IsdA to enhance bacterial cell clumping in the presence of fibrinogen was assessed for S. aureus SH1000 after being cultured to stationary phase $(24 \mathrm{~h})$ in iron-depleted and iron-replenished $(20$ $\mu \mathrm{M} \mathrm{FeCl}_{3}$ ) CL medium and compared to that of S. aureus SRC005 (isd $\mathrm{A}^{-}$) using a method previously described [21,34]. Standardized bacterial suspensions $\left(10^{7} \mathrm{CFU} \mathrm{ml} \mathrm{m}^{-1}\right)$ were concentrated to one fifth of the original culture volume in sterile PBS and each concentration was exposed to serial two-fold dilutions of (fibronectin-depleted) human fibrinogen $\left(2 \mathrm{mg} \mathrm{mL}^{-1}\right.$ serially diluted in sterile PBS). Samples were agitated at $200 \mathrm{rpm}$ for 5 minutes at room temperature and visually examined for bacterial clumping using a light microscope. Clumping titers were recorded as the lowest fibrinogen concentration at which clumping remained visible.

\section{Recombinant protein production}

Presence of target staphylococcal sequences in E. coli expression plasmids were confirmed using automated dye-terminator sequencing (Sequencing Unit, University of Nottingham, UK). Recombinant protein expression from $\mathrm{pQE}$ vector constructs or $\mathrm{pET} 24 \mathrm{~d}$ vector constructs was performed according to vector manufacturer's instructions (Qiagen or Novagen respectively). In brief, overnight E. coli cultures in LB medium with supplemented antibiotics were diluted 1:20 or 1:25 respectively using fresh medium and cultured until an A600 of 0.6 was achieved. Recombinant protein expression was induced by addition of 0.25 or $0.1 \mathrm{mM}$ IPTG respectively (Sigma) with further culture for 3-4 h. Expression cultures were analyzed by

\begin{tabular}{|c|c|}
\hline Strain & Properties \\
\hline \multicolumn{2}{|l|}{ Staphylococcus aureus } \\
\hline $8325-4^{a}$ & Wild type strain (rsbU - mutant) expressing FnBP-A, FnBP-B. NCTC 8325 cured of prophages [43]. \\
\hline DU5883a & FnBP-A, FnBP-B -deficient mutant of 8325-4 (fnbA::tet fnbB::ery) [44]. Tetracycline and Erythromycin resistance. \\
\hline DU5723a & Protein-A-deficient mutant of 8325-4 ( $\Delta$ spa-600::EtBr) [45]. \\
\hline MRSA $^{b}$ & Clinical Meticillin resistant S. aureus arthroplasty isolate. \\
\hline $\mathrm{SH} 1000^{\circ}$ & Wild type 8325-4 derivative strain expressing IsdA $\left(\mathrm{rsbU}^{+}\right)[46]$. \\
\hline $\mathrm{SRC} 005^{\mathrm{c}}$ & IsdA-deficient mutant of SH1000 (isdA::Tn917 ery) [40]. Erythromycin resistance. \\
\hline \multicolumn{2}{|l|}{ Escherichia coli } \\
\hline $514^{\mathrm{a}}$ & E. coli XL1-Blue RecA harbouring plasmid pQE30-fnbA D1-4 [47,48]. Ampicillin resistance. \\
\hline $\mathrm{BL} 21(\mathrm{DE} 3) \mathrm{pSRC} 00^{\circ}$ & E. coli BL21 (DE3) harbouring plasmid pET24d-isdA [40]. Kanamycin resistance. \\
\hline
\end{tabular}

aStrains donated by Professor T. Foster, Trinity College, Dublin, Ireland. Cloning of fnbA D1-4 has been previously described [47,48]. ${ }^{\mathrm{b} S t r a i n s}$ donated by Southport and Ormskirk Hospital, Merseyside, UK. cStrains donated by Professor S. Foster, University of Sheffield, UK. Cloning of isdA has been previously described [40].

Table 1: Bacterial strains. 


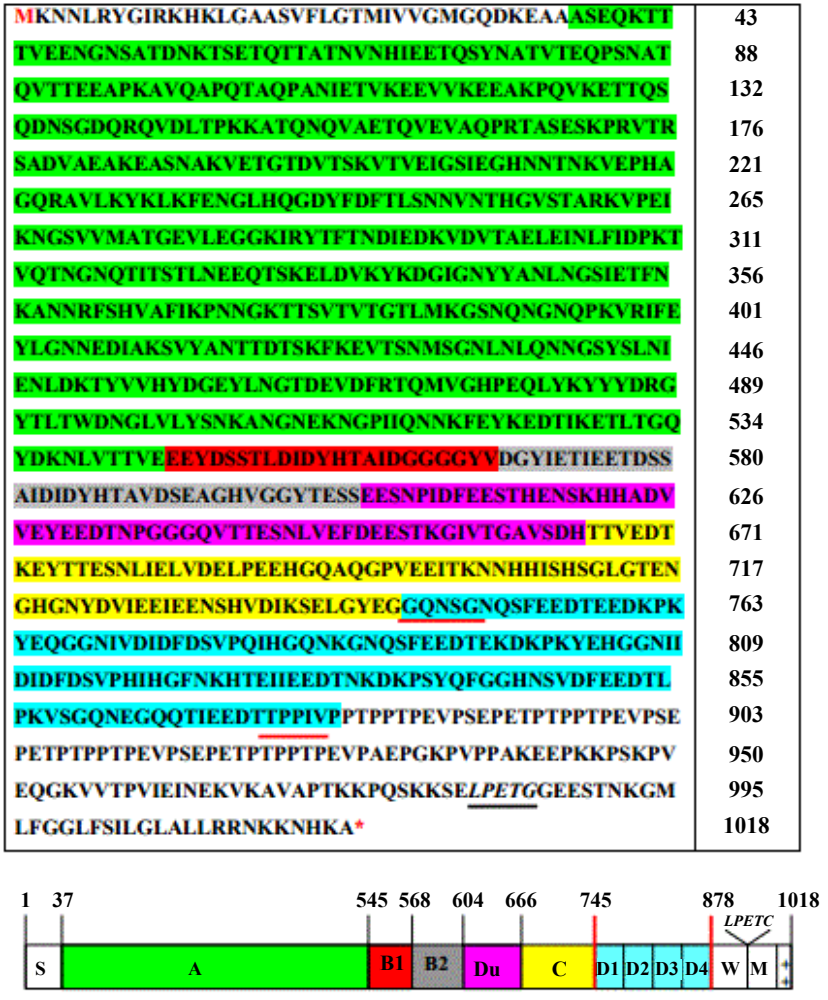

Figure 1: rFnBP-A D1-4 ligand-binding and serum titre ELISA's. A: increasing concentrations of purified rFnBP-A D1-4 were exposed to BSA (closed symbols) or human fibronectin (open symbols) -coated wells and detected using the p-nitrophenyl phosphate system from Sigma. B: Serum titre ELISA using rFnBP-ABCD476-838 (open symbols) and BSA (closed symbols) -coated wells exposed to two fold serial dilutions of rabbit pre-immune serum (diamond symbols), rFnBP D1-4 post-immune serum (square symbols), and an IgG purified fraction of post-immune serum (triangle symbols). All assays were performed in triplicate and values represent the mean absorbance at $405 \mathrm{~nm}$ (A405) with the standard error (error bars are shown in black on all graphs, but are difficult to see in some cases on account of the errors being small).

\begin{tabular}{|lc|}
\hline MTKHYLNSKYQSEQRSSAMKKITMGTASIILGSLVYIGADSQQVN & 45 \\
AATEATNATNNQSTQVSQATSQPINFQVQKDGSSEKSHMDDYMQ & 89 \\
HPGKVIKQNNKYYFQAVLNNASFWKEYKFYNANNQELATTVVND & 133 \\
\hline DKKADTRTINVAVEPGYKSLTTKVHIVVPQINYNHRYTTHLEFEK & 178 \\
AIPTLADAAKPNNVKPVQPKPAQPKTPTEQTKPVQPKVEKVKPAV & 223 \\
TAPSKNENRQTTKVVSSEATKDQSQTQSARTVKTTQTAQDQNKV & 267 \\
QTPVKDVATAKSESNNQAVSDNKSQQTNKVTKQNEVHKQGPSKD $^{-311}$ \\
SKAKELPKTGLTSVDNFISTVAFATLALLGSLSLLLFKRKESK $^{*}$ & 354 \\
\hline
\end{tabular}

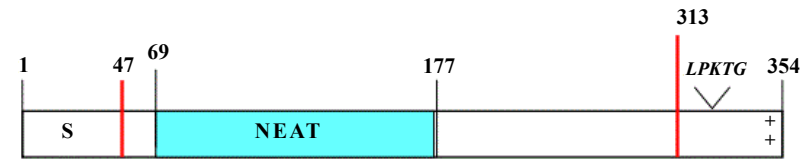

Figure 2: S. aureus $\mathrm{SH} 1000$ IsdA amino acid sequence and schematic organisation. NEAT domain highlighted in light blue, the LPXTG (LPKTG) motif is shown in italic type and underlined in black. The translational start (M) and stop codons $\left({ }^{*}\right)$ are also shown. The amplified domain is highlighted by red lines on the schematic representation and red underlining on the amino acid sequence. Sequence was adapted from Taylor and Heinrichs, 2002, NCBI Accession number AY061874.

SDS PAGE and western transfer [42] with chemiluminescent detection of His6-tagged recombinant protein using anti-his tag monoclonal mouse antibody (Novagen; Merck Chemicals Ltd., Nottingham, UK), goat anti-mouse immunoglobulin horseradish peroxidase-conjugated antibody (Sigma) and the Amersham ECL western blotting detection system (GE Healthcare Ltd., Buckinghamshire, UK).

Recombinant protein purification was performed by metal chelate affinity chromatography using the His-BindTM purification kit according to manufacturer's instructions (Novagen), and chromatography samples were analysed by SDS PAGE and chemiluminescent western immunoblotting as before. Elutions were concentrated using Centriprep centrifugal filter units (Millipore, Watford, UK) and dialysed into sterile phosphate buffered saline (PBS) (Oxoid) using a Slide-A-Lyzer dialysis cassette (ThermoScientific, Rockford, USA). Recombinant protein concentration was determined using the BioRad protein concentration assay (BioRad Laboratories Ltd., Hemel Hempstead, UK).

Functional ligand-binding of recombinant proteins was determined by ELISA [42] using $5 \mu \mathrm{g} \mathrm{ml}^{-1}$ of purified human fibronectin, fibrinogen or bovine serum albumin (BSA) solubilised in sterile PBS for coating of microtitre plate wells (Corning Inc., New York, USA). A 5\% w/v BSA in PBS blocking solution was used and bound His6-tagged recombinant protein was detected using anti-his tag mouse antibody, alkaline phosphatase-conjugated goat anti-mouse antibody (Sigma), and alkaline phosphatase p-nitrophenyl substrate (Sigma). Absorbance was read at $405 \mathrm{~nm}$ (A405) in a BioTek EL800 plate reader (BioTek Instruments Inc., Vermont, USA).

\section{Antiserum production}

Antiserum production was outsourced and performed by Eurogentec Ltd. (Seraing, Belgium) using a standard polyclonal antibody programme. The programme used by Eurogentec Ltd. briefly comprises immunisation of two adult (specific pathogen free) New Zealand White rabbits with $100 \mu \mathrm{g}$ of purified recombinant protein antigen emulsified in complete Freund's adjuvant, followed by three booster immunizations in incomplete Freund's adjuvant over eight weeks. Prior to primary immunization and throughout the immunization schedule, sample bleeds were harvested from both rabbits using sterile Vacutainer-tubes (Table 2 shows the immunization and bleed schedule). A fraction of the final bleed antiserum from one of the immunised rabbits (randomly selected) was IgG-purified on a Staphylococcus aureus Protein G column (Pharmacia), and analysed for purity and concentration by SDS PAGE. Serum titer of antigen-specific antibody was performed by ELISA as described previously using $5 \mu \mathrm{g}$ $\mathrm{ml}^{-1}$ of purified recombinant protein or BSA, BSA blocking solution and application of two-fold serial dilutions of rabbit antiserum in sterile PBS containing $0.1 \% \mathrm{w} / \mathrm{v}$ BSA [43]. Bound antibody was detected as described previously using alkaline phosphatase-conjugated goat antirabbit antibody (Sigma).

\section{ATP bioluminescent adhesion assay}

A static adherence test was selected to assess adherence inhibition

\begin{tabular}{|c|c|c|}
\hline Day & Immunisation & Sample bleed \\
\hline 0 & Primary $(100 \mu \mathrm{g}, \mathrm{CFA})$ & Pre-immune $(2 \mathrm{~mL})$ \\
\hline 14 & Booster $1(100 \mu \mathrm{g}, \mathrm{IFA})$ & \\
\hline 28 & Booster $2(100 \mu \mathrm{g}, \mathrm{IFA})$ & \\
\hline 38 & & Small test bleed $(2 \mathrm{~mL})$ \\
\hline 56 & Booster $3(100 \mu \mathrm{g}, \mathrm{IFA})$ & \\
\hline 66 & & Large test bleed $(20 \mathrm{~mL})$ \\
\hline 87 & & Final bleed $(50-70 \mathrm{~mL})$ \\
\hline
\end{tabular}

Table 2: Standard polyclonal antiserum production schedule. 


\begin{tabular}{|c|c|c|c|c|c|}
\hline \multirow{3}{*}{ 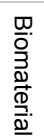 } & Serum & None (distilled water control) & Pre-immune serum & Post-Immune serum & IgG-purified serum \\
\hline & Stainless Steel & $\mathrm{n}=9^{*}$ & $n=9$ & $n=9$ & $n=9$ \\
\hline & Plasma-conditioned Stainless Steel & $\mathrm{n}=9$ & $\mathrm{n}=9$ & $\mathrm{n}=9$ & $n=9$ \\
\hline
\end{tabular}

${ }^{*} n=$ number of individual test reactions, quadruplicate RLU measurements were taken of individual test reactions, thus $n=36$ for RLU measurements.

${ }^{\star *}$ Condition matrix repeated in triplicate (separate experiments) for each test antigen and appropriate bacterial strain.

Table 3: Experimental Condition Matrix**.

\begin{tabular}{|c|c|c|c|c|c|c|c|}
\hline Medium & S. aureus strain & Dilution factor & Average RLU & Amount of ATP & Average CFU & ATP per RLU & ATP per CFU \\
\hline \multirow{4}{*}{ TSB } & $8325-4$ & 41686 & 136.5 & $9.9635^{-7}$ & 312 & $7.2993^{-9}$ & $3.1934^{-9}$ \\
\hline & DU5883 & 41686 & 138.25 & $1.01095^{-6}$ & 310 & $7.3125^{-9}$ & $3.2611^{-9}$ \\
\hline & DU5723 & 41686 & 136.5 & $9.9635^{-7}$ & 312 & $7.2993^{-9}$ & $3.1934^{-9}$ \\
\hline & MRSA & 41687 & 131.25 & $9.5803^{-7}$ & 263 & $7.2993^{-9}$ & $3.6427^{-9}$ \\
\hline \multirow[t]{2}{*}{$\mathrm{CL}$} & SH1000 & 41687 & 67 & $4.8905^{-7}$ & 237 & $7.2993^{-9}$ & $2.0635^{-9}$ \\
\hline & SRC005 & 41686 & 78.41 & $5.7234^{-7}$ & 301 & $7.2993^{-9}$ & $1.9015^{-9}$ \\
\hline
\end{tabular}

Table 4: Value table and calculation for average cellular ATP concentration.

in the presence of other ligands without introducing shear stress and minimizing opportunity for variability, a static test is suitable for initial studies as there is negligible shear at the bone-implant interface. Use of ATP as a biochemical marker for quantifying bacterial adherence to biomaterial surfaces was previously shown to be comparable to conventional methods for viable count determination [32-34]. Prior to adhesion assays, FnBP expression under appropriate culture conditions was confirmed by SDS PAGE and western transfer analysis, and IsdA expression under appropriate culture conditions was confirmed using a bacterial cell clumping assay to assess the ability of IsdA to enhance cell clumping in the presence of fibrinogen after culture in iron-depleted or iron-replete CL medium [21,34].

Standardized exponential phase staphylococcal suspensions $\left(10^{7}\right.$ $\mathrm{CFU} \mathrm{ml}{ }^{-1}$ ) in sterile distilled water with $2 \% \mathrm{v} / \mathrm{v}$ fresh culture medium were prepared and split into four $9.8 \mathrm{~mL}$ aliquots. Table 3 shows the experimental condition matrix for this study. Test aliquots were supplemented with pre-immunized, post-immunized or IgG-purified post-immunized rabbit serum at working antibody titer of 1000 or the equivalent volume of control serum or sterile distilled water. Suspensions were incubated at $37^{\circ} \mathrm{C}$ with $50 \mathrm{rpm}$ shaking for $1 \mathrm{~h}$ for antibody exposure. Suspensions were then aliquoted $(18 \times 0.5 \mathrm{ml})$ for biomaterial exposure to unconditioned medical grade stainless steel coupons ( $5 \mathrm{~mm}$ width, $5 \mathrm{~mm}$ length, $0.25 \mathrm{~mm}$ thickness) (Goodfellow, Huntingdon, UK) or coupons that had been pre-conditioned with pooled normal (non-immunized) rabbit plasma (Cambridge Bioscience Ltd, Cambridge, UK) $(9 \times 0.5 \mathrm{ml}$ each). Exposure was carried out for 1 $\mathrm{h}$ at $37^{\circ} \mathrm{C}$, and coupons were aseptically removed and rinsed prior to bacterial quantification. Adherent bacteria were removed by sonication at $50-60 \mathrm{~Hz}$ for 20 minutes (Ultrawave Ltd., Cardiff, UK) and $100 \mu \mathrm{l}$ of sonicate suspensions were applied in triplicate to wells of an opaque 96-well culture plate (Zeptogen Ltd., Middlesex, UK). Cells were lysed by addition of $100 \mu \mathrm{L}$ of Bactolyse (Cambrex, Rockland, USA) and ATP release was detected in a Microlumat plus LB 96 V luminometer at 595 nm (Berthold Technologies, Redbourn, UK). Triplicate bacterial lawns were also prepared from sonicate suspensions for semi-quantitative confirmation of the relative light unit (RLU) measurements $[44,45]$.

Standard curves of ATP bioluminescence and viable cell numbers were produced for each bacterial strain cultured under standardized conditions to enable accurate conversion of RLU measurements into bacterial colony forming units (CFU, data not shown). The adhesion assay matrix was performed using a single standardized bacterial culture for each strain to be tested, such that the same population of bacterial cells was exposed to the different parameters or immune sera.
Each matrix was repeated in triplicate using fresh bacterial cultures for each experiment. Replicate RLU data from the triplicate matrix assays was pooled $(n>100$ per parameter) and converted into \% average adherent $\mathrm{CFU} \mathrm{ml}{ }^{-1}$.

\section{Statistical analysis}

All un-paired continuous data was displayed as the mean and standard error of the mean. The un-paired t-test (two tailed) was used for comparison of data means and was adjusted for equal or unequal variance using the F-test, a $5 \%$ significance level was adopted $(\mathrm{p}<0.05)$, and where statistical analysis of small sample size data is described, the actual sample size is stated in the text. Where discrete data was obtained and displayed using the sample median and inter-quartile range, the Mann Whitney U-test was used for statistical comparison of sample medians, and a $5 \%$ significance level was adopted $(p<0.05)$.

\section{Results and Discussion \\ rFnBP-A functional ligand and serum titer}

Functional ligand binding of E. coli-expressed soluble rFnBP-A (D1-4) binding domain was assessed by ELISA prior to antiserum production. Statistically significant and specific ligand binding was observed upon exposure to fibronectin (Figure 1A, p<0.001, n=9). Significant increases in fibronectin binding were observed with increasing $r F n B P-A$ D1-4 concentrations $(p<0.05, n=9)$. Strong specific antibody responses were also observed (Figures $3 \mathrm{~A}$ and $3 \mathrm{~B}$ ) with both the un-purified and IgG-purified post-immune serum against immobilised rFnBP-A, compared to that observed with serum collected from rabbits before immunisation (pre-immune serum), and compared to exposure to immobilized BSA ( $\mathrm{p}<0.0001$, unpaired t-test, $\mathrm{n}=4$ per parameter, all tested dilutions). The cut-off was determined as A405 $0.19(\mu+2 \sigma)$ and the endpoint dilution determined as 102,400. A working titer of 1000 was adopted for adhesion assays. Although one would expect some loss of IgG during purification, significant loss was not observed (as evidence by the ELISA) and an equivalent dilution was determined as the appropriate working titer for comparison.

The staphylococcal strains selected for biomaterial adhesion assay analysis of rFnBP-A D1-4 antiserum were the homologous $S$. aureus 8325-4 strain (derived antigen sequence) and two $S$. aureus 8325-4 mutant strains; S. aureus DU5883 which is deficient in $\operatorname{FnBP}(-\mathrm{A},-\mathrm{B})$ expression; and DU5723 which is deficient in Protein-A expression. Additionally, a heterologous clinical MRSA arthroplasty isolate was also selected. Strain validation tests performed prior to adhesion 
Citation: Ratcliffe E (2014) Staphylococcus aureus Binding Proteins for Prevention of Orthopaedic Implant-Related Infections. J Microb Biochem Technol 6: 303-313. doi:10.4172/1948-5948.1000160

assays included confirmation of bacterial strain properties (expression or non-expression of FnBP); confirmation of expression throughout the bacterial growth phase and during adherence assay culture; determination of cellular ATP levels for each strain; and validation of adhesion assay sensitivity under standardized conditions (Table 4, Figures $4 \mathrm{~A}$ and $4 \mathrm{~B}$ ). Assay sensitivity for the desired application was determined as minimum RLU detection at $595 \mathrm{~nm}$ of 150, which equates to $5 \times 10^{2} \mathrm{CFU}$.

To convert RLU $(595 \mathrm{~nm})$ to $\mathrm{CFU} \mathrm{m} \mathrm{m}^{-1}$ :

$$
\mathrm{CFU} \mathrm{ml}{ }^{-1}=10 \times[\operatorname{RLU} \times(\mathrm{ATP} \text { per RLU }) /(\mathrm{ATP} \text { per CFU) }]
$$

\section{rFnBP-An antibody inhibition of bacterial binding}

Figure 5 shows the adherence assay results for S. aureus DU5883 (FnBP mutant), 8325-4 (homologous), DU5723 (Protein A mutant),
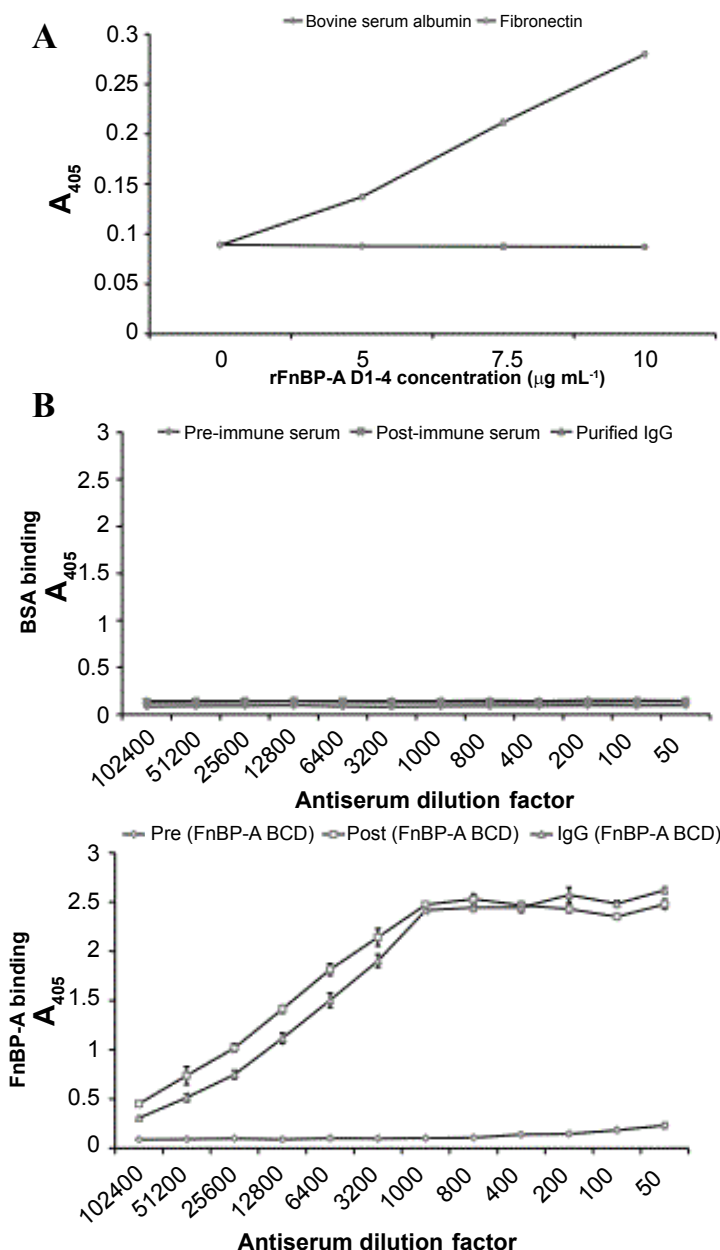

Figure 3: rFnBP-A D1-4 ligand-binding and serum titre ELISA's.

A: increasing concentrations of purified $\mathrm{rFnBP}-\mathrm{A}$ D1-4 were exposed to BSA (closed symbols) or human fibronectin (open symbols) -coated wells and detected using the p-nitrophenyl phosphate system from Sigma. B: Serum titre ELISA using rFnBP-A BCD476-838 (open symbols) and BSA (closed symbols) -coated wells exposed to two-fold serial dilutions of rabbit pre-immune serum (diamond symbols), rFnBP D1-4 post-immune serum (square symbols), and an IgG purified fraction of post-immune serum (triangle symbols). All assays were performed in triplicate and values represent the mean absorbance at $405 \mathrm{~nm}$ (A405) with the standard error (error bars are shown in black on all graphs, but are difficult to see in some cases on account of the errors being small).
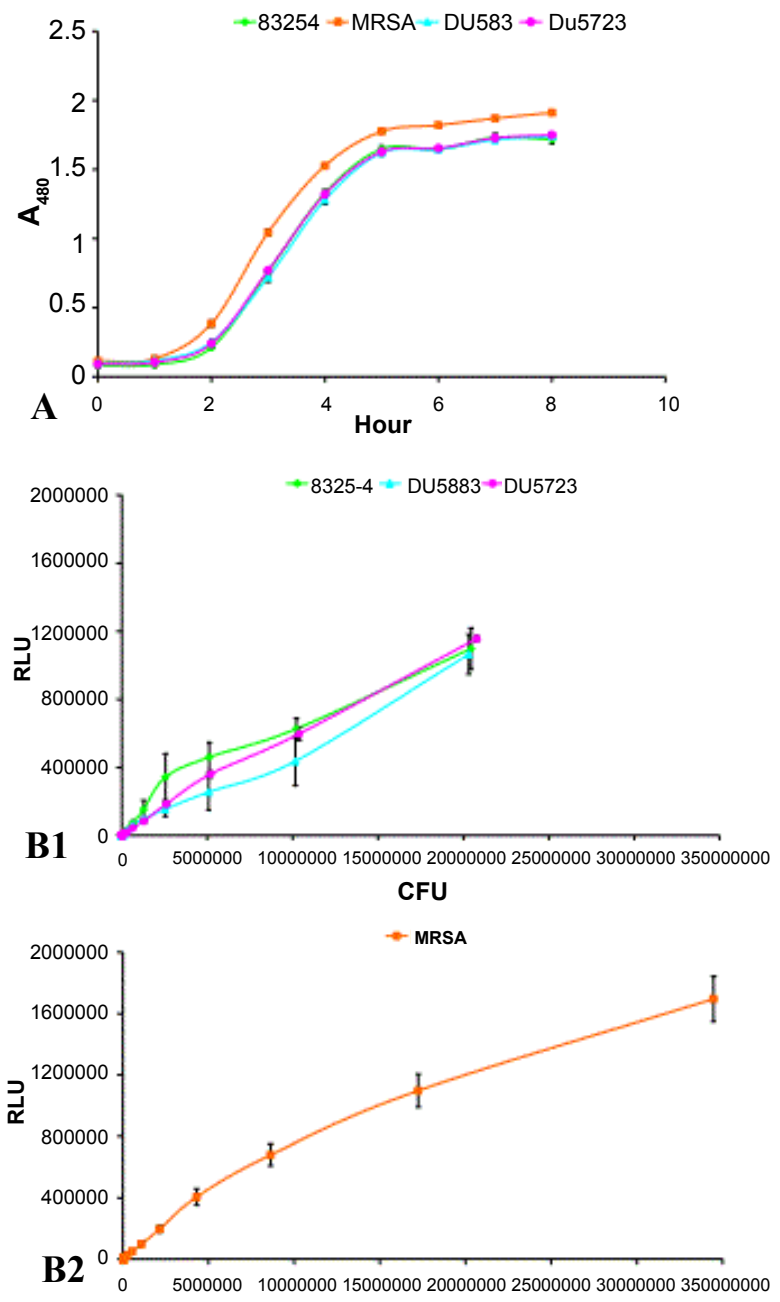

CFU

Figure 4: Standard Curves.

A. Replication phase standard curves. S. aureus 8325-4, DU5883, DU5723, and the MRSA arthroplasty isolate cultured in TSB with incorporated tetracycline and erythromycin for $S$. aureus DU5883. Assays were performed in triplicate and the mean absorbance at $490 \mathrm{~nm}$ (A490) with the standard error was plotted against culture time. B. Viable cell number standard curves. Cell density (CFU) and ATP-bioluminescence emitted from serially diluted standardised cultures of S. aureus 8325-4, DU5883, DU5723 (B1) and the MRSA arthroplasty isolate (B2) cultured in TSB with incorporated tetracycline and erythromycin for $S$. aureus DU5883. Assays were performed in triplicate and the mean relative light units (RLU) at 595nm (A595) with standard error was plotted against average CFU (error bars are shown in black on all graphs but are difficult to see in some cases on account of the errors being small).

and the MRSA arthroplasty isolate after exposure to antiserum (raised against rFnBP-A D1-4) and plasma-conditioned steel coupons. Bacterial adherence to a plasma-conditioning film without inhibitory antiserum exposure was significantly greater ( $<<0.001$, Figure $5 \mathrm{~A}$ ) with FnBP-expressing strains compared to $S$. aureus DU5883, thus further demonstrating the importance of fibronectin-binding via FnBP.

Exposure to pre-immune serum significantly promoted the adhesion of all bacterial strains above the levels observed without antiserum exposure ( $<<0.003$, Figure $5 A$ ), but for $S$. aureus DU5883 this promoted adherence remained significantly lower than that observed for strains expressing FnBP $(\mathrm{p}<0.0001$, Figure $5 \mathrm{~A})$. This promotion of adhesion through pre-exposure to serum protein is likely mediated 

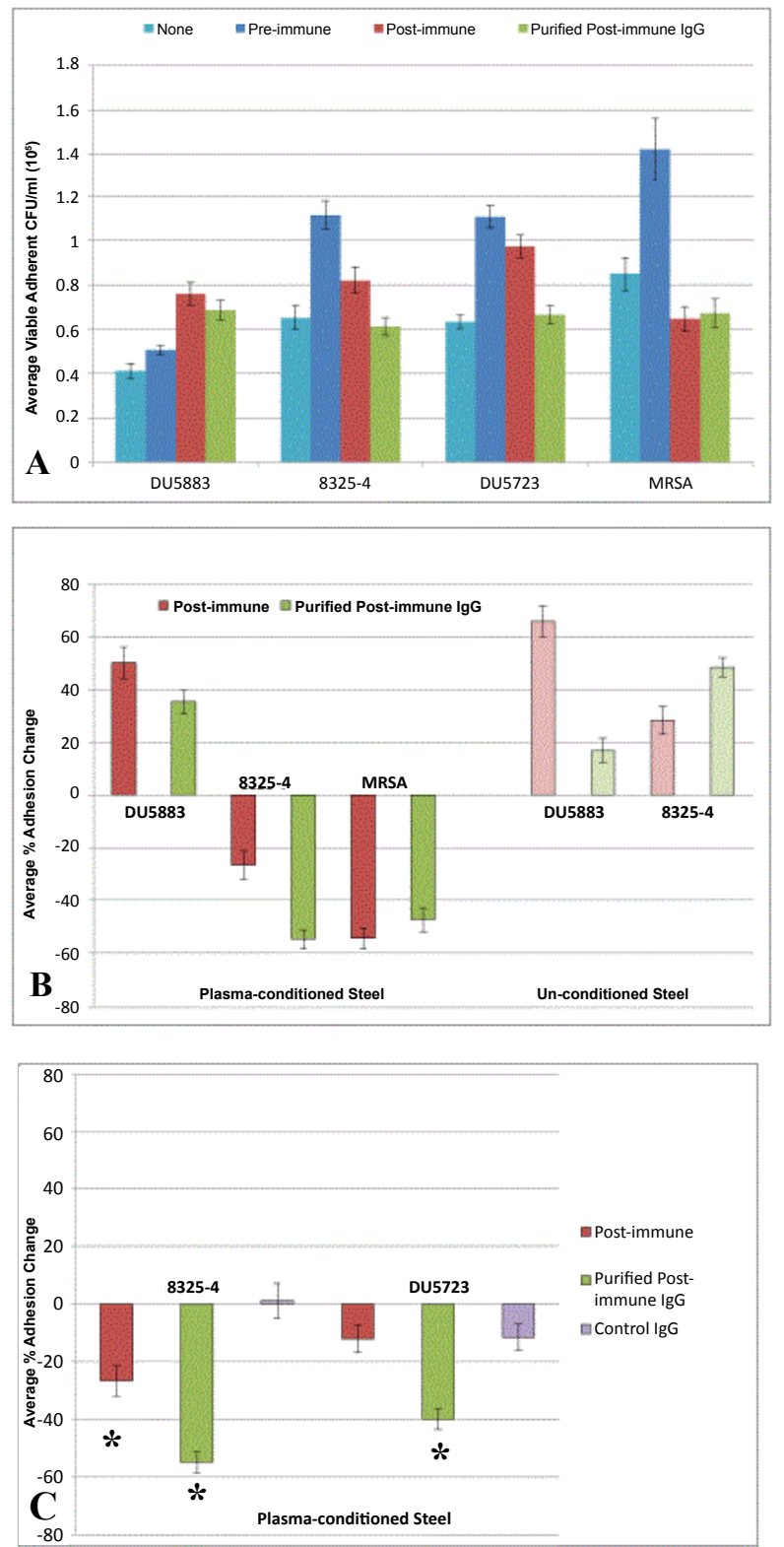

Figure 5: Adhesion assays with rFnBP-A D1-4 antiserum.

A. Adherence of standardised cultures of $S$. aureus 8325-4, DU5883 (FnBPA/B-deficient mutant), DU5723 (Protein A-deficient mutant), and MRSA to rabbit plasma-conditioned stainless steel coupons, with or without prior antiserum exposure (working titre of 1000 , controls sterile deionised $\mathrm{H}_{2} \mathrm{O}$ ). B. Normalised mean adherence change expressed as a percentage of the adherence in presence of pre-immune serum to plasma-conditioned or unconditioned stainless steel coupons for $S$. aureus 8325-4, DU5883 and MRSA with exposure to $\mathrm{rFnBP}-\mathrm{A}$ post-immune or purified IgG post-immune serum. All results were statistically significantly different to pre-immune serum exposure. C. Normalised mean adherence change expressed as a percentage of the adherence in presence of pre-immune serum to plasma-conditioned stainless steel coupons for S. aureus 8325-4 and DU5723 with exposure to rFnBP-A post-immune, rFnBP-A purified IgG post-immune serum or control purified IgG serum (*denotes a statistically significant $p<0.05$ difference to pre-immune serum exposure).

In all cases adherence was quantified by ATP-bioluminescence and culture. Assays were performed in triplicate and values represent the mean adherent CFU ml-1 or mean \% adherent CFU ml-1 with standard error of pooled data ( $\mathrm{n}>100$ per parameter, error bars are shown in black). Sample means were compared by un-paired t-test adjusted for equal or unequal sample variances, significance level was $p<0.05$. through staphylococcal surface protein interaction, in part via FnBP (evidenced by the reduction observed with the mutant strain), but also through non-FnBP interactions such as clumping factor binding of fibrinogen and fibronectin, Protein A interactions as well as nonspecific interactions.

Post-immune serum exposure significantly reduced adhesion of both the homologous $S$. aureus 8325-4 and heterologous MRSA arthroplasty isolate when compared to pre-immune serum exposure $(-26.5 \% \mathrm{p}<0.0007,-54.5 \% \mathrm{p}<0.0001$ respectively, Figure $5 \mathrm{~B})$, whereas adhesion of $S$. aureus DU5883 was significantly enhanced by exposure to post-immune serum $(+50.3 \% \mathrm{p}<0.0001$, Figure $5 \mathrm{~B})$. Promotion of $S$. aureus DU5883 adherence above the level observed with pre-immune serum does not involve FnBP but may be related to immunisation and other unknown alterations this has caused. The opposite results of significantly reduced and significantly promoted adhesion after exposure to post-immune serum observed with S. aureus 8325-4 and DU5883 respectively, suggests that the reduced adhesion observed for S. aureus $8325-4$ is related to reduced fibronectin-binding capacity and possibly the presence of adhesion-inhibitory rFnBP-A (D-domain) antibody.

To clarify whether the results observed with post-immune serum were IgG-related the adherence assay was also performed after exposure to purified IgG from a fraction of the post-immune serum. Equivalent levels of adhesion to that observed with un-purified postimmune serum were observed with the purified $\operatorname{IgG}$ fraction for all three strains $(8325-4 ;-54.8 \% \mathrm{p}<0.0001, \mathrm{MRSA} ;-47.4 \% \mathrm{p}<0.0001$, DU5883; $+35.5 \% \mathrm{p}<0.0004$, compared to pre-immune serum exposure, Figure 5B). This suggests that the reduced adhesion observed with $S$. aureus 8325-4 and the MRSA arthroplasty isolate is in part related to adhesion-inhibitory IgG interactions resulting from immunisation with rFnBP-A (D1-4). The fact that a further significant reduction in adhesion to plasma-conditioned steel was observed for S. aureus 8325-4 after exposure to purified IgG compared to whole post-immune serum supports this result $(-28.3 \% \mathrm{p}=0.004)$. A significant effect on adhesion of $S$. aureus DU5883 after exposure to purified IgG compared to unpurified post-immune serum was not observed. Instead an equivalent level of significant adhesion-enhancement was observed. Thus further supporting the theory that adhesion-inhibitory rFnBP-A (D-domain) antibody is responsible for the reduced adhesion observed with FnBPexpressing strains, and that the adhesion promotion observed with $S$. aureus DU5883 is partly due to non-specific IgG interactions.

The significant reductions in staphylococcal adhesion to plasmaconditioned steel observed after exposure to hyperimmune serum were not observed on adhesion to un-conditioned steel, and in fact opposite results were observed. Adhesion of $S$. aureus 8325-4 to un-conditioned steel was significantly promoted to equivalent levels after exposure to un-purified and IgG purified post-immune serum compared to the level of adhesion observed after exposure to pre-immune serum $(+28.4 \% \mathrm{p}=0.01,+48.5 \% \mathrm{p}<0.0001$ respectively, Figure $5 \mathrm{C})$. In addition to this, adhesion of $S$. aureus DU5883 to un-conditioned steel was also significantly promoted above the levels observed with pre-immune serum exposure, after exposure to un-purified and IgG-purified postimmune serum $(+66 \% \mathrm{p}<0.0001,+17 \% \mathrm{p}=0.053$ respectively, Figure $5 \mathrm{C})$. These results confirm that the significantly reduced adhesion of homologous S. aureus 8325-4 after exposure to rFnBP-A D1-4 postimmune serum (un-purified and IgG-purified) in the presence of a plasma-conditioning film is specifically related to adhesion-inhibitory IgG interactions resulting from immunization with rFnBP-A D1-4 and the presence of the plasma glycoprotein conditioning film, of which 
fibronectin is a major constituent, thus further supporting the presence of adhesion-inhibitory rFnBP-A-specific antibody.

As staphylococcal Protein A binds host IgG by the Fc region, effectively coating the bacterial cell with host antibody in the wrong orientation for signalling host immune responses, it is logical to suggest that pre-incubating bacterial cells with antiserum could lead to some of the effects observed in the adherence tests being related to Protein A interactions. Therefore involvement of Protein A was investigated using a Protein A mutant derivative of $S$. aureus 8325-4. Adhesion of S. aureus DU5723 to plasma-conditioned steel was almost identical to that observed for S. aureus 8325-4 for each parameter tested, with significant promotion after pre-immune serum exposure $(+75 \%, p<0.0001$, Fig $5 \mathrm{~A})$ and significant (non-Protein A mediated) inhibition after exposure to rFnBP-A-immunised purified IgG $(-39.9 \%$, $\mathrm{p}<0.0001$, Figure 5C). Reduced adhesion was observed after exposure to un-purified post-immune serum, but the levels were not as great as those observed with $S$. aureus $8325-4$ and did not achieve statistical significance $(-12.1 \% \mathrm{p}=0.07$, Figure $5 \mathrm{C})$. In fact, the difference in the level of adhesion observed after exposure to un-purified post-immune serum between the two strains was near-significant statistically $(p=0.052$, Figure $5 C)$. Purified IgG from sham immunized rabbits acted as a control to determine whether any other constituent of the purified IgG from immunized rabbits was responsible for the adhesioninhibitory effects observed. Adhesion after exposure to the purified IgG sham control was equivalent for both strains and no statistical difference was observed (Figure 5C).

Taken together, and since significant inhibition was not observed with either strain and exposure to sham control IgG, the results suggest that inhibition of adhesion with purified $\operatorname{IgG}$ from a rabbit that was immunized with rFnBP-A D1-4 is specifically related to immunization and the interaction between generated antibody and staphylococcal FnBP-A. The near significant un-purified post-immune serum results suggest some possible involvement of protein $\mathrm{A}$ in the complete test system. However in the more specific test system using rFnBP-Aimmunized and sham control IgG fractions, the presence or absence of Protein A had negligible effect on the adhesion levels observed after exposure to either of these fractions. Significant inhibitory activity was observed with the immunized IgG fraction whereas no significant difference in adhesion was observed with the sham control IgG fraction, suggesting no involvement of Protein A-IgG specific interactions. Speculatively, it is possible that an unknown direct or indirect Protein A interaction with other constituents of the un-purified post-immune serum may be enhancing the adhesion-inhibitory activity observed with the non-mutant strain (8325-4).

\section{rIsdA functional ligand, serum titer and bacterial expression}

Statistically significant and specific functional ligand binding was observed upon exposure of purified rIsdA to fibrinogen (Figure $6 \mathrm{~A}, \mathrm{p}<0.001, \mathrm{n}=9$ ). Significant increases in fibrinogen binding were observed with increasing rIsdA concentrations $(\mathrm{p}<0.001, \mathrm{n}=9)$. Hyperimmune serum showed strong specific responses against immobilised rIsdA, compared to pre-immune serum and exposure to immobilized BSA at all antibody dilutions tested $(\mathrm{p}<0.0001$, unpaired t-test, $\mathrm{n}=4$ per parameter, Figure $6 \mathrm{~B}$ ). The cut-off was determined as A405 $0.16(\mu+2 \sigma)$ and the endpoint dilution determined as 102,400 (purified IgG titer was not significantly different). A working titer of 1000 was adopted for adhesion assays.

The staphylococcal strains selected for biomaterial adhesion assay analysis of rIsdA antiserum were the homologous S. aureus SH1000
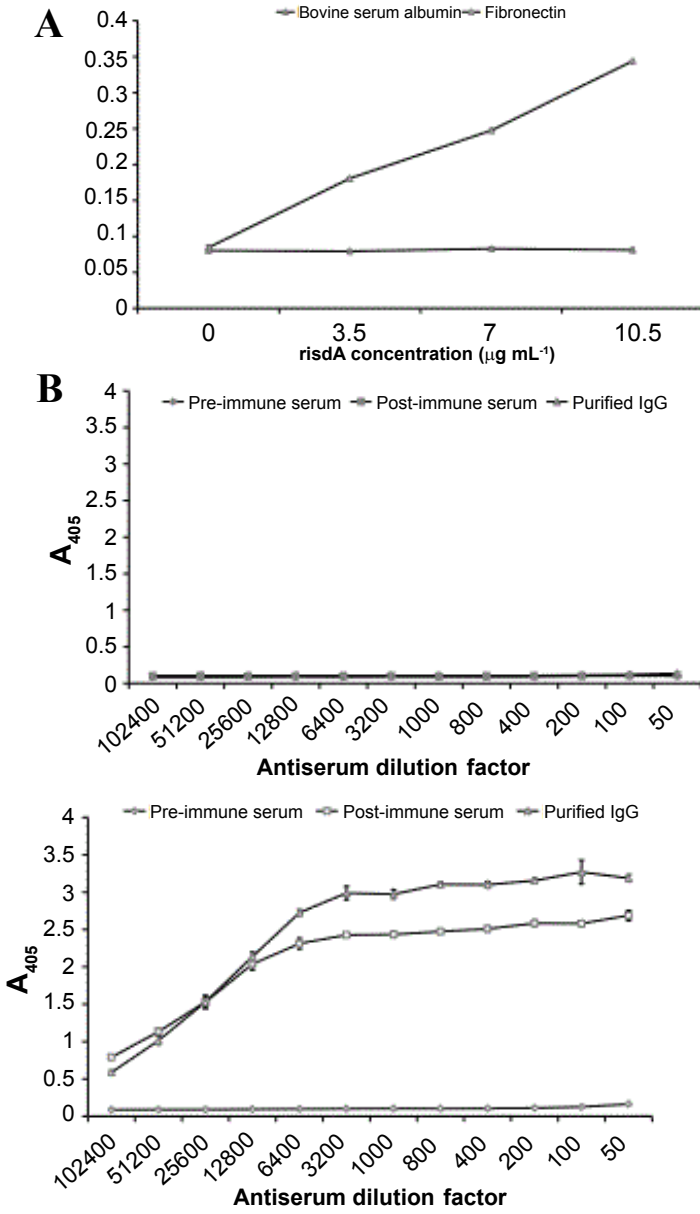

C

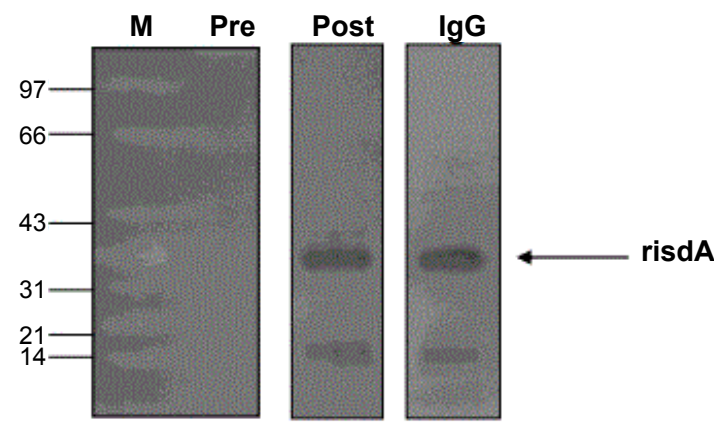

Figure 6: rlsdA ligand-binding and serum titre ELISA's.

$A$ : increasing concentrations of purified rlsdA were exposed to BSA (closed symbols) or human fibrinogen (open symbols) -coated wells and detected using the p-nitrophenyl phosphate system from Sigma. B: Serum titre ELISA using rlsdA (open symbols) and BSA (closed symbols) -coated wells exposed to two-fold serial dilutions of rabbit pre-immune serum (diamond symbols), rlsdA post-immune serum (square symbols), and an IgG purified fraction of post-immune serum (triangle symbols). All assays were performed in triplicate and values represent the mean absorbance at $405 \mathrm{~nm}$ (A405) with the standard error (error bars are shown in black on all graphs, but are difficult to see in some cases on account of the errors being small). Image $C$ shows specific rlsdA detection by western immunoblotting using rlsdA post-immune serum and the purified $\lg$ fraction (IgG) compared to the rabbit pre-immune serum (Pre). M represents the SDS PAGE (low range) molecular weight marker from BioRad. 
strain (8325-4 derivative strain, derived antigen sequence) and the derived mutant strain $S$. aureus SRC005 which is IsdA-deficient (Figure 6C). Prior to performing the adherence tests, the same series of validation assays were performed as described for rFnBP-A, with an additional validation assays to determine growth and expression of IsdA under iron-limiting conditions.

Optimal expression of IsdA by S. aureus SH1000 was previously shown after $18 \mathrm{~h}$ of culture into stationary phase in iron-limited medium (CL medium) that was representative of in-vivo conditions [34]. Under these in vitro iron-limiting conditions, the fibrinogen clumping titre of $S$. aureus increases when IsdA is expressed on the cell surface [34]. Bacterial cell clumping was assessed for S. aureus SH1000 after being cultured to stationary phase in iron-depleted and iron-replenished CL medium and compared to that of $S$. aureus SRC005 (isdA ${ }^{-}$) using a method previously described (Figure 7A) [21,34]. Visual examples of bacterial clumping in decreasing fibrinogen concentrations and the PBS control are also shown (Figure 7B). Culture in iron-limited CL medium significantly promoted the cell clumping ability of $S$. aureus SH1000 in the presence of fibrinogen (median titer $3.91 \mu \mathrm{g} \mathrm{ml}^{-1}$ ) compared to culture in iron-replenished CL medium $\left(7.81 \mu \mathrm{g} \mathrm{ml}^{-1}\right)$, and compared to the cell clumping ability of $S$. aureus SRC005 in either CL $(7.81 \mu \mathrm{g}$ $\left.\mathrm{m}^{-1}\right)$ or $\mathrm{CL} \mathrm{FeCl}_{3}$ medium $\left(7.81 \mu \mathrm{g} \mathrm{m}^{-1}\right)(\mathrm{p}<0.02$, Mann-Whitney $\mathrm{U}$ test, $n=7$ per parameter). Similar clumping titers were observed for

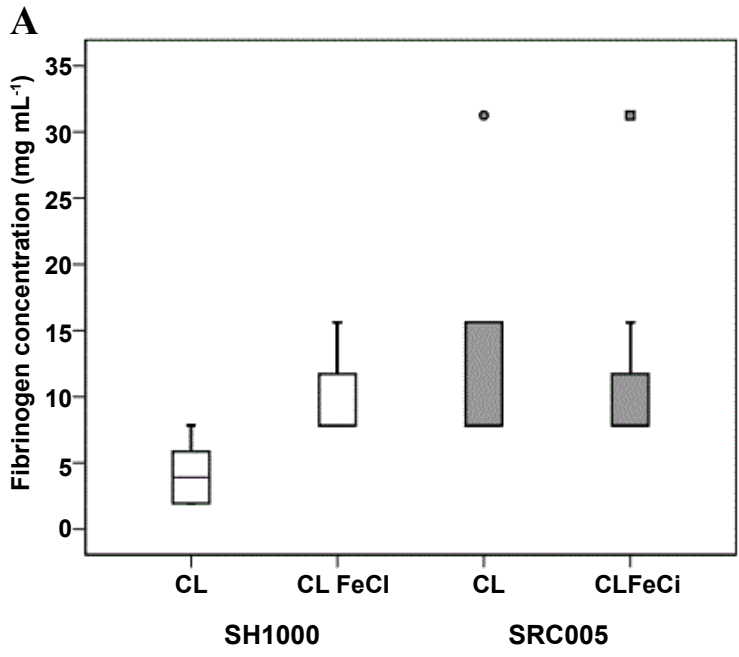

B

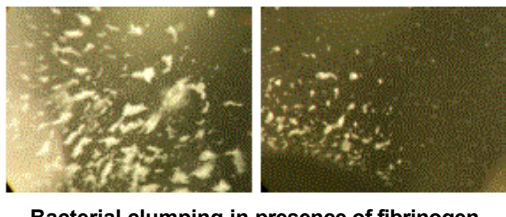

Bacterial clumping in presence of fibrinogen

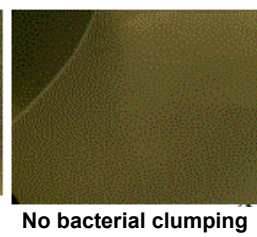

in PBS control

Figure 7: Bacterial cell clumping assay.

A: standardised suspensions of $\mathrm{S}$. aureus $\mathrm{SH} 1000$ and SRC005 cultured in iron-depleted or iron-replenished $\mathrm{CL}$ medium $\left(\mathrm{CL}, \mathrm{CLFeCl}_{3}\right)$ were assayed for the ability of cell surface-exposed IsdA to enhance cell clumping in the presence of purified human fibrinogen. Clumping titers were recorded as the lowest fibrinogen concentration at which clumping remained visible. The box and whisker plots show the median line, the $75^{\text {th }}$ and $25^{\text {th }}$ percentiles (box) and the data range (whisker). Outlier values (circle symbols) fall $1.5-3$ box lengths from the $75^{\text {th }} / 25^{\text {th }}$ percentile, and extreme values (square symbols) fall $>3$ box lengths from the $75^{\text {th }} / 25^{\text {th }}$ percentile. B: example images of bacterial clumping in decreasing fibrinogen concentrations and under control conditions.
S. aureus SH1000 and SRC005 after culture in iron-replete medium, which differ only in their ability to express IsdA. Enhanced clumping was observed with $S$. aureus SH1000 under iron-limited conditions only. Taken together the data suggest that the significant promotion of cell-mediated clumping in the presence of fibrinogen above the levels observed where other proteins such as clumping factors (ClfA, ClfB) are primarily responsible is directly related to optimal expression of IsdA. The data also suggest that $1 \mu \mathrm{M} \mathrm{ml}^{-1}$ iron chloride is sufficient for repression of IsdA expression equivalent to that of a non-expressing mutant strain, as previously demonstrated for IsdB [46-49].

Replication phase and viable cell number standard curves were produced for S. aureus SH1000 and SRC005 when cultured in CL, CL $\mathrm{FeCl}_{3}$ and TSB medium (Figure 8A). As optimal expression of IsdA was shown previously after $18 \mathrm{~h}$ culture in CL medium, this same culture time was adopted for the adherence tests. There was no difference in bacterial cell density when strains were cultured in $\mathrm{CL}$ or $\mathrm{CL} \mathrm{FeCl}_{3}$ medium. However, cell density was significantly reduced for both strains in either of these media when compared to standard culture in TSB medium $(\mathrm{p}<0.05$, unpaired $\mathrm{t}$-tests, $\mathrm{n}=3$ per parameter, all time points, Figure $8 \mathrm{~B}$ ). Previous research has shown that $S$. aureus $\mathrm{SH} 1000$ exhibits a decreased lag phase before exponential growth [46] and an increased growth yield compared to $S$. aureus $8325-446$, [50] and these differences along with production of staphyloxanthin (orange pigment) [41] were also observed in this study (data not shown). $S$. aureus $\mathrm{SH} 1000$ has a functional rsbU and restored $\sigma \mathrm{B}$ regulatory activity [46-48] which in addition to the culture conditions could impart differences on the expression and repertoire of binding proteins between these strains. Increased adhesion to fibronectin-coated or fibrinogen-coated surfaces was demonstrated in S. aureus BB255 ( $\sigma \mathrm{B}$ deficient, rsbU mutation) after complementation with rsbU and in a $\sigma \mathrm{B}$-overproducing derivative strain [51].

\section{rIsdA antibody inhibition of bacterial binding}

Figure 9 shows the adherence assay results for S. aureus SH1000 and SRC005 after exposure to antiserum (raised against rIsdA) and plasma-conditioned steel coupons. Bacterial adherence to a plasmaconditioning film without antiserum exposure was significantly greater for IsdA-deficient $S$. aureus SRC005 (average increase of $+19.9 \%$ $\mathrm{p}<0.049$, Figure 9A) than that observed for S. aureus SH1000. In the complete test system, as observed with $S$. aureus 8325-4, exposure to pre-immune serum significantly promoted the adhesion of $S$. aureus SH1000 compared to adhesion without antiserum exposure $(+65.1 \%$ $\mathrm{p}<0.003$, Figure 9A), whereas no effect was observed on $S$. aureus SRC005 adhesion under the same conditions. Previous research has shown a significant role of IsdA in the promotion of heme-iron scavenging from host haemoglobin in the pathogenesis of infection [39]. Taken together, the results suggest that in the presence of unbound serum constituents, IsdA is a potent adhesin and IsdA-mediated bacterial adherence to plasma-conditioned biomaterial is significantly promoted ( $<<0.02$, SH1000 vs. SRC005, Figure 9A).

Post-immune serum exposure significantly increased adhesion of both strains when compared to pre-immune serum exposure, and the level of promotion with $S$. aureus $\mathrm{SH} 1000$ was significantly greater than SRC005 (SH1000; +68.1\% p $<0.02$, SRC005; +61.1\% $\mathrm{p}<0.0001$, Figure 9B; $\mathrm{p}<0.02$, SH1000 vs. SRC005, Figure 9A). The data suggest partial involvement of IsdA, however the results with the post-immune serum are paramount for indicating the efficacy of any adhesioninhibitory antibody that may have been raised against rIsdA; as an inhibitory effect must be observed in the presence of other potential in vivo interactions and other staphylococcal binding ligands. Opposing 

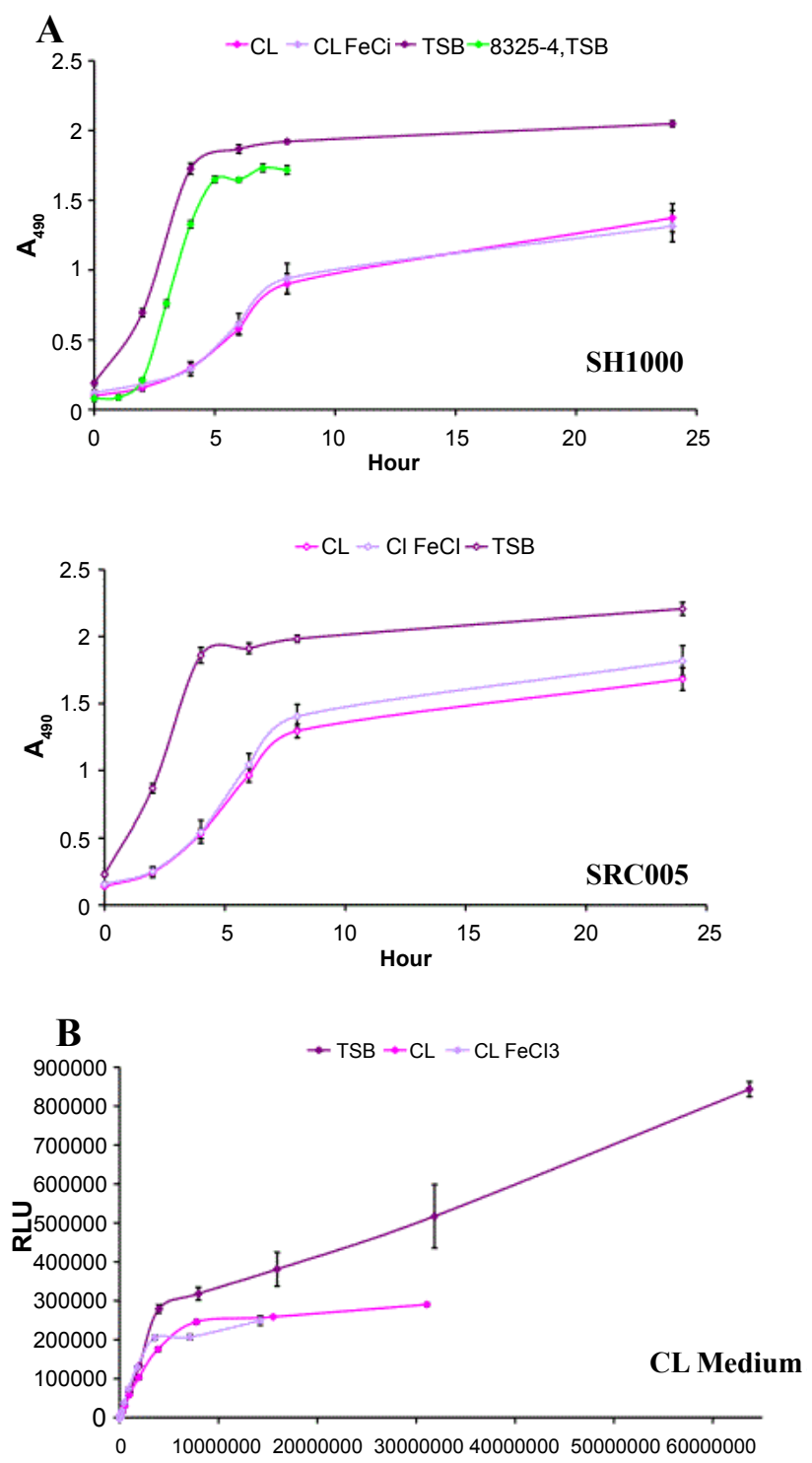

CFU

Figure 8: Standard Curves.

A. Replication phase standard curves. S. aureus $\mathrm{SH} 1000$ and S. aureus SRC005 cultured in TSB, iron-limited, or iron replenished CL medium (CL, $\mathrm{CL} \mathrm{FeCl}_{3}$ ) with incorporated erythromycin for culture of $\mathrm{S}$. aureus SRC005. Assays were performed in triplicate and the mean absorbance at $490 \mathrm{~nm}$ (A490) with the standard error plotted against culture time. B. Viable cell number standard curves. Cell density (CFU) and ATP-bioluminescence emitted from standardised cultures of $S$. aureus $\mathrm{SH} 1000$ in TSB, CL, or CL $\mathrm{FeCl}_{3}$ medium. Assays were performed in triplicate and the mean relative light units (RLU) at $595 \mathrm{~nm}$ (A595) with standard error plotted against average CFU (error bars are shown in black on all graphs, but are difficult to see in some cases on account of the errors being small).

results were observed after exposure to the purified IgG fraction of the post-immune serum. A highly significant reduction of adhesion was observed with S. aureus SH1000 compared to exposure to pre-immune serum $(-57.9 \% \mathrm{p}<0.0001$, Figure $9 \mathrm{~B})$ and compared to un-purified post-immune serum $(-126.0 \% \mathrm{p}<0.0001$, Figure $9 \mathrm{~B})$. Whereas purified $\mathrm{IgG}$ was shown to significantly promote the adherence of $S$. aureus SRC005 compared to pre-immune serum exposure $(+52.6 \% \mathrm{p}<0.0001$, Figure $9 \mathrm{~B}$ ) and this promotion was equivalent to that observed after exposure to un-purified post-immune serum for this strain. As the two strains differ only in expression of IsdA, the data suggest that the reduced adhesion observed with $S$. aureus $\mathrm{SH} 1000$ could be related to IsdA-specific adhesion-inhibitory IgG. Although not fully elucidated in the current study, if protein A or non-rIsdA specific IgG were involved, similar and not opposing results would be expected. Taken together, although IsdA-inhibitory IgG may be present the efficacy of inhibitory activity appears insufficient to overcome other available adhesive interactions when bacteria are exposed to the full complement of serum constituents.

Adhesion of both strains to un-conditioned steel was significantly reduced without exposure to antiserum (S. aureus SH1000; $-41 \%$ $\mathrm{p}<0.0001, S$. aureus SRC005; $-36.3 \% \mathrm{p}<0.0001)$. Yet the same trend that was observed in the presence of a plasma-conditioning film of a significantly higher level of adhesion with S. aureus SRC005 compared to $S$. aureus SH1000 was also observed $(+4.7 \% \mathrm{p}<0.001)$. Although formal conclusions cannot be drawn from the current assay, as the two strains differ only by presence and absence of IsdA, the results were
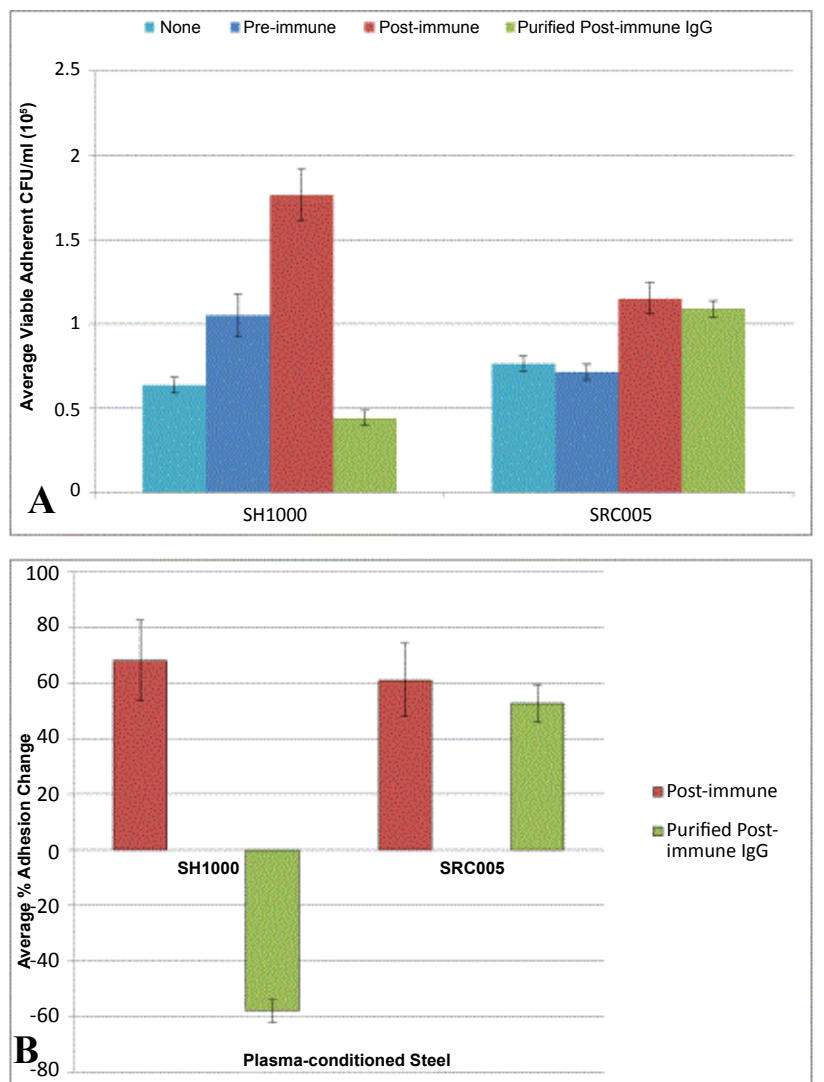

Figure 9: ATP-bioluminescent adhesion assays with rlsdA antiserum.

A. Adherence of standardised cultures of S. aureus SH1000 and SRC005 (IsdA-deficient mutant) to rabbit plasma-conditioned stainless steel coupons, with or without prior antiserum exposure (working titre of 1000 , controls sterile deionised $\mathrm{H}_{2} \mathrm{O}$ ). B. Normalised mean adherence change expressed as a percentage of the adherence in presence of pre-immune serum to plasmaconditioned stainless steel coupons for S. aureus SH1000 and SRC005 with exposure to rlsdA post-immune or purified IgG post-immune serum. All results were statistically significantly different to pre-immune serum exposure. In all cases adherence was quantified by ATP-bioluminescence and culture. Assays were performed in triplicate and values represent the mean adherent CFU ml${ }^{-1}$ or mean $\%$ adherent CFU ml- ${ }^{-1}$ with standard error of pooled data $(n>100$ per parameter, error bars are shown in black). Sample means were compared by un-paired t-test adjusted for equal or unequal sample variances, significance level was $p<0.05$. 
possibly related to absence of IsdA allowing other bacterial cell surface interactions to preside. A general reduction in adhesion of both strains to unconditioned biomaterial may be related to the binding protein repertoire of these strains. However during this study, only IsdA presence was determined. The level of adhesion of $S$. aureus SH1000 and SRC005 to un-conditioned steel was not significantly affected by exposure to any antiserum. Adhesion in the presence of pre-immune serum, post-immune serum and IgG-purified post-immune serum was equivalent to that observed without antiserum exposure, and equivalent to each parameter, suggesting that the results observed in the presence of a plasma-conditioning film are related to the presence of deposited plasma constituents.

\section{Conclusion}

This study assessed the ability of antibody raised against $\mathrm{rFnBP}-\mathrm{A}$ and rIsdA to inhibit $S$. aureus adhesion to plasma-conditioned biomaterial in vitro. Significant inhibitory activity was observed with rFnBP hyperimmune serum against homologous and heterologous $S$. aureus regardless of virulence; significant equivalent inhibition was observed with the MRSA arthroplasty isolate. Inhibitory responses appeared to be specifically related to $\mathrm{rFnBP}-\mathrm{A}$ immunization and particularly to the generation of anti-rFnBP-A adhesion-inhibitory IgG. As evidenced by the observation of inhibitory responses against FnBP-expressing strains only; in the presence of a plasma-conditioning film (fibronectin presence); with purified IgG fractions of post-immune serum; as well as opposite promotion of adhesion with an FnBPdeficient mutant strain; and inhibition did not involve protein A or non-FnBP / sham IgG. The findings clearly emphasize the potential of $S$. aureus $\mathrm{rFnBP}-\mathrm{A} \mathrm{D}$-domain as an important candidate for a multicomponent vaccine to prevent $S$. aureus implant infections.

A significant inhibitory response was also observed with antirIsdA IgG against homologous $S$. aureus and appeared to be specific as evidenced by the inhibition against IsdA-expressing strains only; in the presence of a plasma-conditioning film (fibrinogen/fibronectin presence); as well as opposite promotion of adhesion with an IsdAdeficient mutant strain. However, this inhibitory response was not retained in the complete test system where bacteria were exposed to the full complement of serum constituents. Full rIsdA was used in this study and it is possible that use of the NEAT domain of this protein may lead to a more specific binding spectrum of elicited antibody and increased inhibitory activity due to a reduction in immunological epitopes not responsible for ligand binding. IsdA should also be investigated for other aspects of implant infection establishment and related protective mechanisms given that there have been conflicting reports as to whether rIsdA elicited antibody can promote complementdependent opsonophagocytic clearance of staphylococci $[38,39]$ and more recently anti-rIsdA antibody has been shown to interfere with staphylococcal heme-iron scavenging mechanisms [39].

A multi-component vaccine against staphylococcal implant infection would require elements that elicit cumulative inhibitory responses through multiple independent routes such as adhesion inhibition, biofilm inhibition and regulatory interference. As described in this study there is enormous potential to utilise binding proteins to target general bacterial adhesion, further binding proteins that may have direct involvement at the implant interface include bone sialoprotein binding protein and the serine-aspartate repeat ( $\mathrm{Sdr}$ ) proteins, which may impart enhanced inhibitory activity. Utilizing intercellular adhesins (ica locus) to target biofilm formation could potentially provide cross-inhibitory protection against other major causative organisms such as $S$. epidermidis. A concept that could also be incorporated into consideration of the type of adjuvant, for example cell wall fatty acid composition of particular Propionibacterium acnes strains show similar immuno-stimulatory properties to $M$. tuberculosis $[52,53]$ and was previously shown to stimulate TH1 cell-mediated immunity in leukaemia patients $[54,55]$. As $P$. acnes is thought to be a largely under-estimated cause of orthopaedic implant infections, incorporating this organism as an adjuvant is an attractive concept, with added potential benefit of extending vaccine spectrum to target P. acnes.

\section{Acknowledgement}

The author would like to thank Professor Roger Bayston (Biomaterials-Related Infection Group) and Professor Brigitte E. Scammell, Division of Orthopaedic and Accident Surgery, Queen's Medical Centre, Nottingham NG7 2UH, UK, where the work was carried out. The author also thanks the Nottingham Orthopaedic Research Appeal-Nottingham Hospitals Charity for grant support, Professor Timothy Foster (Trinity College, Dublin, Ireland) for donation of $S$. aureus 83254, DU5883, DU5723, and E. coli 514, and Professor Simon Foster (University of Sheffield, UK) for donation of S. aureus SH1000, SRC005, and E. coli BL21 (DE3) pSRC001.

\section{References}

1. Harkess J, Daniels A (2003) Arthroplasty; Introduction and Overview, p. 223 242. In T. Canale T (ed), Campbell's Operative Orthopaedics, 10th ed. Mosby Inc. Philadelphia.

2. Bernard L, Hoffmeyer P, Assal M, Vaudaux P, Schrenzel J, et al. (2004) Trends in the treatment of orthopaedic prosthetic infections. J Antimicrob Chemother 53: $127-129$.

3. Barberán J, Aguilar L, Carroquino G, Giménez MJ, Sánchez B, et al. (2006) Conservative treatment of staphylococcal prosthetic joint infections in elderly patients. Am J Med 119: 993.

4. Davis N, Curry A, Gambhir AK, Panigrahi H, Walker CR, et al. (1999) Intraoperative bacterial contamination in operations for joint replacement. $J$ Bone Joint Surg Br 81: 886-889.

5. Nixon M, Jackson B, Varghese P, Jenkins D, Taylor G (2006) Methicillinresistant Staphylococcus aureus on orthopaedic wards: incidence, spread, mortality, cost and control. J Bone Joint Surg Br 88: 812-817.

6. Kilgus DJ, Howe DJ, Strang A (2002) Results of periprosthetic hip and knee infections caused by resistant bacteria. Clin Orthop Relat Res: 116-124.

7. Kourbatova EV, Halvosa JS, King MD, Ray SM, White N, et al. (2005) Emergence of community-associated methicillin-resistant Staphylococcus aureus USA 300 clone as a cause of healthcare-associated infections among patient with prosthetic joint infections. Am J Infect Control 33: 385-391.

8. Tenover F. 2005. The real vancomycin-resistant Staphylococcus aureus has arrived. Clin Microbiol Newsletter 27: 35-40.

9. Pfeltz RF, Wilkinson BJ (2004) The escalating challenge of vancomycin resistance in Staphylococcus aureus. Curr Drug Targets Infect Disord 4: 273294.

10. Schmitz FJ, FluitAC, Hafner D, BeeckA, Perdikouli M, et al. (2000) Development of resistance to ciprofloxacin, rifampin, and mupirocin in methicillin-susceptible and -resistant Staphylococcus aureus isolates. Antimicrob Agents Chemother 44: 3229-3231.

11. Charbonneau P1, Parienti JJ, Thibon P, Ramakers M, Daubin C, et al. (2006) Fluoroquinolone use and methicillin-resistant Staphylococcus aureus isolation rates in hospitalised patients: a quasi-experimental study. Clin Infect Dis. 42: 778-784.

12. Williams I, Venables WA, Lloyd D, Paul F, Critchley I (1997) The effects of adherence to silicone surfaces on antibiotic susceptibility in Staphylococcus aureus. Microbiology $143: 2407-2413$.

13. Proctor RA, Kahl B, von Eiff C, Vaudaux PE, Lew DP, et al. (1998) Staphylococcal small colony variants have novel mechanisms for antibiotic resistance. Clin Infect Dis 27 Suppl 1: S68-74.

14. Saginur R, Stdenis M, Ferris W, Aaron SD, Chan F, et al. (2006) Multiple combination bactericidal testing of staphylococcal biofilms from implantassociated infections. Antimicrob Agents Chemother 50: 55-61. 
Citation: Ratcliffe E (2014) Staphylococcus aureus Binding Proteins for Prevention of Orthopaedic Implant-Related Infections. J Microb Biochem Technol 6: 303-313. doi:10.4172/1948-5948.1000160

15. Götz F (2002) Staphylococcus and biofilms. Mol Microbiol 43: 1367-1378.

16. Weigel LM, Donlan RM, Shin DH, Jensen B, Clark NC, et al. (2007) Highlevel vancomycin-resistant Staphylococcus aureus isolates associated with a polymicrobial biofilm. Antimicrob Agents Chemother 51: 231-238.

17. Delmi M, Vaudaux P, Lew DP, Vasey H (1994) Role of fibronectin in staphylococcal adhesion to metallic surfaces used as models of orthopaedic devices. J Orthop Res 12: 432-438.

18. Vaudaux PE, François P, Proctor RA, McDevitt D, Foster TJ, et al. (1995) Use of adhesion-defective mutants of Staphylococcus aureus to define the role of specific plasma proteins in promoting bacterial adhesion to canine arteriovenous shunts. Infect Immun 63: 585-590.

19. Herrmann M, Vaudaux PE, Pittet D, Auckenthaler R, Lew PD, et al. (1988) Fibronectin, fibrinogen, and laminin act as mediators of adherence of clinical staphylococcal isolates to foreign material. J Infect Dis 158: 693-701.

20. Tunney MM, Patrick S, Gorman SP, Nixon JR, Anderson N, et al. (1998) Improved detection of infection in hip replacements. A currently underestimated problem. J Bone Joint Surg Br 80: 568-572.

21. Wann ER, Gurusiddappa S, Hook M (2000) The fibronectin-binding MSCRAMM FnbpA of Staphylococcus aureus is a bifunctional protein that also binds to fibrinogen. J Biol Chem 275: 13863-13871.

22. Roche FM, Downer R, Keane F, Speziale P, Park PW, et al. (2004) The $\mathrm{N}$-terminal A domain of fibronectin-binding proteins $\mathrm{A}$ and $\mathrm{B}$ promotes adhesion of Staphylococcus aureus to elastin. J Biol Chem 279: 38433-38440.

23. Heilmann C, Niemann S, Sinha B, Herrmann M, Kehrel BE, et al. (2004) Staphylococcus aureus fibronectin-binding protein (FnBP)-mediated adherence to platelets, and aggregation of platelets induced by FnBPA but not by FnBPB. J Infect Dis 190: 321-329.

24. Fitzgerald R, Loughman A, Keane F, Brennan M, Knobel M, et al. (2006) Fibronectin-binding proteins of Staphylococcus aureus mediate activation of human platelets via fibrinogen and fibronectin bridges to integrin GPIIb/IIla and IgG binding to the Fc? Rlla receptor. Mol Microbiol 59: 212-230.

25. Massey RC, Kantzanou MN, Fowler T, Day NP, Schofield K, et al. (2001) Fibronectin-binding protein A of Staphylococcus aureus has multiple substituting, binding regions that mediate adherence to fibronectin and invasion of endothelial cells. Cell Microbiol 3: 839-851.

26. Schwarz-Linek U, Höök M, Potts JR (2006) Fibronectin-binding proteins of gram-positive cocci. Microbes Infect 8: 2291-2298.

27. Peacock SJ, Day NP, Thomas MG, Berendt AR, Foster TJ (2000) Clinical isolates of Staphylococcus aureus exhibit diversity in fnb genes and adhesion to human fibronectin. J Infect 41: 23-31.

28. Arciola CR, Campoccia D, Gamberini S, Baldassarri L, Montanaro L (2005) Prevalence of cna, fnbA and $\mathrm{fnbB}$ adhesin genes among Staphylococcus aureus isolates from orthopedic infections associated to different types of implant. FEMS Microbiol Lett 246: 81-86.

29. Moore PC, Lindsay JA (2002) Molecular characterisation of the dominant UK methicillin-resistant Staphylococcus aureus strains, EMRSA-15 and EMRSA-16. J Med Microbiol 51: 516-521.

30. Saunders NA, Underwood A, Kearns AM, Hallas G (2004) A virulenceassociated gene microarray: a tool for investigation of the evolution and pathogenic potential of Staphylococcus aureus. Microbiology 150: 3763-3771.

31. Cassat JE, Dunman PM, McAleese F, Murphy E, Projan SJ, et al. (2005) Comparative genomics of Staphylococcus aureus musculoskeletal isolates. J Bacteriol 187: 576-592.

32. Schennings T, Heimdahl A, Coster K, Flock Jl (1993) Immunization with fibronectin binding protein from Staphylococcus aureus protects against experimental endocarditis in rats. Microb Pathogen 15: 227-236.

33. Mamo W, Jonsson P, Flock JI, Lindberg M, Müller HP, et al. (1994) Vaccination against Staphylococcus aureus mastitis; immunological response of mice vaccinated with fibronectin binding protein (FnBP-A) to challenge with Staphylococcus aureus. Vaccine 12: 988-992.

34. Clarke SR, Wiltshire MD, Foster SJ (2004) IsdA of Staphylococcus aureus is a broad spectrum, iron-regulated adhesin. Mol Microbiol 51: 1509-1519.

35. Vermeiren CL, Pluym M, Mack J, Heinrichs DE, Stillman MJ, et al. (2006) Characterization of the heme binding properties of Staphylococcus aureus IsdA. Biochemistry. 45: 12867-12875.
36. Mazmanian SK, Skaar EP, Gaspar AH, Humayun M, Gornicki P, et al. (2003) Passage of heme-iron across the envelope of Staphylococcus aureus. Science 299: 906-909.

37. Wiltshire MD, Foster SJ (2001) Identification and analysis of Staphylococcus aureus components expressed by a model system of growth in serum. Infect Immun 69: 5198-5202.

38. Stranger-Jones YK, Bae T, Schneewind O (2006) Vaccine assembly from surface proteins of Staphylococcus aureus. Proc Natl Acad Sci U S A 103 16942-16947.

39. Kim HK, DeDent A, Cheng AG, McAdow M, Bagnoli F, et al. (2010) IsdA and IsdB antibodies protect mice against Staphylococcus aureus abscess formation and lethal challenge. Vaccine 28: 6382-6392.

40. Clarke SR, Brummell KJ, Horsburgh MJ, McDowell PW, Mohamad SA et al. (2006) Identification of in vivo-expressed antigens of Staphylococcus aureus and their use in vaccinations for protection against nasal carriage. J Infect Dis 193: 1098-1108.

41. Horsburgh MJ, Ingham E, Foster SJ (2001) In Staphylococcus aureus, fur is an interactive regulator with PerR, contributes to virulence, and Is necessary for oxidative stress resistance through positive regulation of catalase and iron homeostasis. J Bacteriol 183: 468-475.

42. Mayer MP (1995) A new set of useful cloning and expression vectors derived from pBlueScript. Gene 163: 41-46.

43. Novick R (1967) Properties of a cryptic high-frequency transducing phage in Staphylococcus aureus. Virology 33: 155-166.

44. Greene C, McDevitt D, Francois P, Vaudaux PE, Lew DP, et al. (1995) Adhesion properties of mutants of Staphylococcus aureus defective in fibronectin-binding proteins and studies on the expression of fnb genes. Mol Microbiol 17: 11431152.

45. Patel AH, Nowlan P, Weavers ED, Foster $T$ (1987) Virulence of protein A-deficient and alpha-toxin-deficient mutants of Staphylococcus aureus isolated by allele replacement. Infect Immun 55: 3103-3110.

46. Horsburgh MJ, Aish JL, White IJ, Shaw L, Lithgow JK, et al. (2002) sigmaB modulates virulence determinant expression and stress resistance: characterization of a functional rsbU strain derived from Staphylococcus aureus 8325-4. J Bacteriol 184: 5457-5467.

47. Roche FM, Downer R, Keane F, Speziale P, Park PW, et al. (2004) The $\mathrm{N}$-terminal $\mathrm{A}$ domain of fibronectin-binding proteins $\mathrm{A}$ and $\mathrm{B}$ promotes adhesion of Staphylococcus aureus to elastin. J Biol Chem 279: 38433-38440.

48. O'Connell DP, Nanavaty T, McDevitt D, Gurusiddappa S, Höök M, et al. (1998) The fibrinogen-binding MSCRAMM (clumping factor) of Staphylococcus aureus has a Ca2+-dependent inhibitory site. J Biol Chem 273: 6821-6829.

49. Kuklin NA, Clark DJ, Secore S, Cook J, Cope LD, et al. (2006) A nove Staphylococcus aureus vaccine: Iron surface determinant B induces rapid antibody responses in rhesus macaques and specific increased survival in a murine S. aureus sepsis model. Infect Immun 74: 2215-2223.

50. Giachino P, Engelmann S, Bischoff M (2001) Sigma(B) activity depends on RsbU in Staphylococcus aureus. J Bacteriol 183: 1843-1852.

51. Entenza JM, Moreillon P, Senn MM, Kormanec J, Dunman PM, et al. (2005) Role of sigmaB in the expression of Staphylococcus aureus cell wall adhesins ClfA and FnbA and contribution to infectivity in a rat model of experimental endocarditis. Infect Immun 73: 990-998.

52. Azuma I, Sugimura K, Taniyama T, Aladin A, Yamamura Y (1975) Chemica and immunological studies on the cell walls of Propionibacterium acnes strain C7 and Corynebacterium parvum ATCC 11829. Jpn J Microbiol 19: 265-275.

53. Julák J, Bednár M, Turecek F, Mára M (1984) Fatty acid composition of a Propionibacterium acnes vaccine and its relationship to immunostimulatory activity. Zentralbl Bakteriol Mikrobiol Hyg A 258: 296-309.

54. Hokland P, Ellegaard J, Heron I (1980) Immunomodulation by Corynebacterium parvum in normal humans. J Immunol 124: 2180-2185.

55. Hokland P, Ellegaard J (1985) Immunomodulation of NK and ADCC by Corynebacterium parvum in acute myeloid leukaemia patients. Leuk Res 9: 175-184. 